Pontifícia Universidade Católica $_{\text {Do Rio de Janeiro }}$
Und

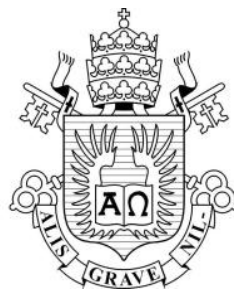

Aline Rodrigues Botelho

\author{
Embalagens e produtos para \\ cuidado com as roupas: \\ uma análise da percepção ecológica no \\ discurso dos consumidores
}

Dissertação de Mestrado

Dissertação apresentada como requisito parcial para obtenção do grau de Mestre pelo Programa de PósGraduação em Design do Departamento de Artes \& Design da PUC-Rio.

Orientador: Prof. Alfredo Jefferson de Oliveira 


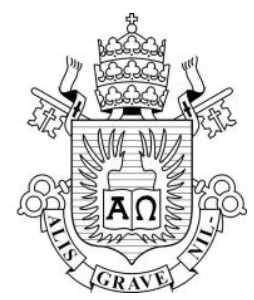

Aline Rodrigues Botelho

\author{
Embalagens e produtos para \\ cuidado com as roupas: \\ uma análise da percepção ecológica no \\ discurso dos consumidores
}

Dissertação apresentada ao Programa de PósGraduação em Design da PUC-Rio como requisito parcial para obtenção do grau de Mestre em Design. Aprovada pela Comissão Examinadora abaixo assinada.

Prof. Alfredo Jefferson de Oliveira

Orientador

Departamento de Artes \& Design - PUC-Rio

Profa. Vera Lucia Moreira dos Santos Nojima

Departamento de Artes \& Design - PUC-Rio

Profa. Claudia Rocha Mourthé

Universidade Federal do Rio de Janeiro - UFRJ

Profa. Denise Berruezo Portinari

Coordenadora Setorial do Centro de Teologia

e Ciências Humanas - PUC-Rio

Rio de Janeiro, 09 de Abril de 2012 
Todos os direitos reservados. É proibida a reprodução total ou parcial do trabalho sem autorização da universidade, do autor e do orientador.

\section{Aline Rodrigues Botelho}

Graduou-se em Desenho Industrial com habilitação em Programação Visual pela Universidade Federal do Espírito Santo, Ufes, em 2008.

Ficha Catalográfica

Botelho, Aline Rodrigues

Embalagens e produtos para cuidado com as roupas: uma análise da percepção ecológica no discurso dos consumidores / Aline Rodrigues Botelho ; orientador: Alfredo Jefferson de Oliveira. - 2012.

157 f. : il. (color.) ; $30 \mathrm{~cm}$

Dissertação (mestrado)-Pontifícia Universidade Católica do Rio de Janeiro, Departamento de Artes e Design, 2012.

Inclui bibliografia

1. Artes e design - Teses. 2. Consumo. 3. Produtos para o cuidado com a roupa. 4. Embalagens. 5. Sustentabilidade. 6. Design. I. Oliveira, Alfredo Jefferson de. II. Pontifícia Universidade Católica do Rio de Janeiro. Departamento de Artes \& Design. IV. Título. 
Para os que sempre acreditaram. 


\section{Agradecimentos}

Em primeiro lugar a Deus por me permitir mais esta conquista.

A meu orientador, pelas indicações, experiências e incentivos.

À PUC-Rio e a CAPES pelas bolsas concedidas.

Aos meus pais, Marco e Lucia, por todo amor, apoio e compreensão incondicional

Ao meu irmão Thomaz, por toda ajuda direta e indiretamente

A minha amiga Monica, por esses dois anos de paciência, parceria e grandes lições.

Ao meu amigo Thiago, pelas leituras, conversas, fotografias e apoio nos piores momentos.

A minha prima Marcia, pela disponibilidade sem igual e que, sem sua ajuda certamente teria me faltado muita coragem.

A minha prima Isabela pelo carinho, atenção e muitas correções e opiniões.

As minhas amigas de mestrado, Chiara e Jucélia, pelas conversas de incentivo e tranquilidade.

A minha amiga Leilane pela presteza e disponibilidade sempre.

Aos entrevistados, pelo convite aceito, disponibilidade em ajudar e contribuir com meu projeto através de suas experiências.

Aos meu amigos, que direta ou indiretamente acompanharam e incentivaram minha trajetória. E ainda compreenderam minha total falta de atenção.

Às professoras que gentilmente aceitaram participar da comissão examinadora.

E aos funcionários do Departamento de Artes e Design, pelos constantes auxílios. 


\section{Resumo}

Botelho, Aline Rodrigues; Oliveira, Alfredo Jefferson de (orientador). Embalagens e produtos para cuidado com as roupas: uma análise da percepção ecológica no discurso dos consumidores. Rio de Janeiro, 2012. 157p. Dissertação de Mestrado - Departamento de Artes \& Design, Pontifícia Universidade Católica do Rio de Janeiro.

Esta dissertação tem como foco principal investigar de que maneira os consumidores avaliam os produtos disponíveis no mercado e quais critérios utilizam para efetuar sua compra, limitando o estudo apenas aos produtos para cuidados com as roupas. Por ter um enfoque na sustentabilidade, o nicho de consumidores se restringiu aos que se identificam com algum tipo de ação relacionada ao meio ambiente. Em um primeiro momento, foi realizada uma pesquisa de caráter qualitativo, com onze participantes. Esta entrevista se deu com o intuito de investigar o que os consumidores avaliavam como critério de escolha, na hora da compra. Em um segundo instante, foi realizado outro estudo, com os mesmos participantes, buscando entender qual a referência do termo sustentabilidade, para eles e, ainda, como relacionam os critérios citados na primeira entrevista com as marcas e seus respectivos produtos. Os depoimentos revelaram que os quesitos de sustentabilidade e de produtos ditos ecológicos revelados na primeira entrevista, na maioria das vezes, funcionam apenas como conceituação, visto que ao se depararem com a imagem das marcas ou de seus produtos, tais características não são percebidas ou mencionadas.

\section{Palavras-chave}

Consumo; produtos para o cuidado com a roupa; embalagens; sustentabilidade; design. 


\section{Abstract}

Botelho, Aline Rodrigues; Oliveira; Alfredo Jefferson de (Advisor). Packings and products fot cloth care: an analysis of the ecological perception on the consumers discourse. Rio de Janeiro, 2012. 157p. Dissertation - Departamento de Artes \& Design, Pontifícia Universidade Católica do Rio de Janeiro.

The main focus of this dissertation is, to investigate in which way the consumers evaluate the products available in the market and what criteria they use to make their decision, limited only to cloth care products. By having its focus on sustainability, the consumer niche was restricted to the ones that identify themselves with some kind of action related to the environment. At first, was carried a qualitative research, with eleven participants. This interview was done with the intention of investigating what the consumers evaluate as choice criteria, at the time of purchase. In a second moment, another study was conducted, with the same participants, seeking to understand what is their reference to the term sustainability, and also how they relate the criteria mentioned in the first interview with the brands and their respective products. The statements revealed that, the questions of sustainability and of products claimed to be ecological revealed in the first research, most of the times work only as conceptualization, since, when confronted with the image of the brands or their products, such questions are not perceived or mentioned.

\section{Keywords}

Consumption; cloth care products; packing; sustainability; design. 


\section{Sumário}

Apresentação 18

1 Introdução 9

1.1. Estrutura da dissertação 13

2 Análise do consumo 15

2.1. O consumo brasileiro 18

2.2. Nova vertente de consumo: o consciente 22

3 Impactos ambientais e design sustentável 26

3.1. Breve panorama da sustentabilidade 30

4 Produtos e Embalagens $\quad 37$

4.1. Requisitos para aplicar a sustentabilidade 41

4.2. Alternativas de baixo impacto 44

5 Produtos para cuidado com a roupa 48

5.1. Perfil dos fabricantes 49

5.1.1. Embalagens 51

5.1.2. Rótulo 52

5.1.3. Transporte 52

5.1.4. Biodegradabilidade 53

5.2. Análise dos fabricantes 53

5.2.1. Bombril 53

5.2.1.1. Mon Bijou 
5.2.1.2. Ecobril 56

5.2.2. Cassiopéia 60

5.2.2.1. Biowash 60

5.2.3. Procter \& Gamble - P\&G 62

5.2.3.1. Ace 63

5.2.3.2. Ariel 65

5.2.4. Unilever 66

5.2.4.1. Comfort 68

5.2.4.2. Fofo 71

5.2.4.3. Omo 73

5.2.4.4. Surf 75

5.2.5. Ypê 77

5.2.5.1. Tixan Ypê

5.2.5.2. Amaciante Ypê 79

5.2.5.3. Ypê Premium $\quad 80$

6 Posicionamento dos consumidores: pesquisa de campo 83

6.1. Metodologia de Explicitação do Discurso Subjacente (MEDS) 83

6.1.1. Objetivo 83

6.1.2. Sujeitos 83

6.1.2.1. Critério de seleção dos entrevistados 84

6.1.2.2. O anonimato dos entrevistados 85

6.1.2.3. Abordagem dos participantes 85

6.1.2.4. Escolha do ambiente: real x virtual 86

6.1.3. Entrevista piloto e roteiro 87

6.1.4. Coleta de dados 88

6.1.5. Analise do material 89

6.2. Resultado da pesquisa de campo 90

6.2.1. Apresentação dos entrevistados 90

6.2.2. Eixo temático 1: consumo 91

6.2.2.1. Produtos escolhidos 91

6.2.2.2. Tradição no cuidado com a roupa 92

6.2.2.3. O uso do amaciante 92 
6.2.2.4. Novidade atrelada à satisfação

6.2.3. Eixo temático 2: critérios para o consumo 94

6.2.3.1. Preço 94

6.2.3.2. Perfume 96

6.2.3.3. Facilidade no trabalho 96

6.2.4. Eixo temático 3: embalagem 97

6.2.4.1. Aspecto visual 97

6.2.4.2. Tamanho 98

6.2.4.3. Refil, Reciclável, Reutilizável 98

6.2.5. Eixo temático 4: produtor 99

6.2.5.1. Conhecimento da marca 99

6.2.5.2. Posicionamento dos fabricantes 100

6.2.6. Eixo temático 5: maneiras de buscar informações sobre o produto 101

6.2.6.1. Propaganda 102

6.2.6.2. Rótulo 103

6.2.7. Eixo temático 6: meio ambiente 104

6.2.7.1. Menos produto 104

6.2.7.2. Biodegradável 106

6.2.7.3. Consumidores 106

6.3. Pesquisa complementar 107

6.3.1. Objetivo 107

6.3.2. Sujeitos 108

6.3.3. Elaboração do material 108

6.3.4. Forma de aplicação da pesquisa 109

6.3.5. Análise das respostas 109

6.4. Resultado da pesquisa complementar 110

6.4.1. Categoria 1: Sustentabilidade 110

6.4.2. Categoria 2: Marcas 111

6.4.2.1. Ace 111

6.4.2.2. Ariel 112

6.4.2.3. Biowash 112

6.4.2.4. Comfort 113

6.4.2.5. Ecobril 113 
6.4.2.6. Fofo 114

6.4.2.7. Mon Bijou 114

6.4.2.8. Omo 114

6.4.2.9. Surf 115

6.4.2.10. Ypê 115

6.4.3. Categoria 3: Sabão em pó 116

6.4.3.1. Ariel 116

6.4.3.2. Omo 116

6.4.3.3. Ace 117

6.4.3.4. Tixan Ypê 117

6.4.3.5. Ecobril 118

$\begin{array}{ll}\text { 6.4.3.6. Surf } & 118\end{array}$

6.4.3.7. Mon Bijou 119

6.4.4. Categoria 4: Sabão líquido 120

6.4.4.1. Ariel 120

6.4.4.2. Tixan Ypê 121

$\begin{array}{ll}\text { 6.4.4.3. Omo } & 121\end{array}$

6.4.4.4. Biowash 121

6.4.4.5. Ecobril 122

6.4.4.6. Mon Bijou 122

6.4.4.7. Surf 123

6.4.5. Categoria 5: Amaciante 123

6.4.5.1. Ypê 123

6.4.5.2. Fofo 124

$\begin{array}{ll}\text { 6.4.5.3. Mon Bijou } & 124\end{array}$

6.4.5.4. Comfort 124

6.4.5.5. Comfort concentrado 125

6.4.5.6. Fofo concentrado 125

6.4.5.7. Mon Bijou concentrado 126

6.4.5.8. Ecobril 126

7 Discussão dos resultados 128

7.1. Posicionamento da empresa: análise da marca 128 
$\begin{array}{ll}\text { 7.2. Propaganda } & 131\end{array}$

7.3. Aspecto visual e sua relação com a sustentabilidade 133

$\begin{array}{ll}\text { 7.3.1. Cor } & 133\end{array}$

7.3.2. Tamanho e concentração 134

$\begin{array}{ll}\text { 7.3.3. O rótulo e suas indicações } & 135\end{array}$

$\begin{array}{ll}\text { 7.4. Reciclável, Refil e Reutilizável } & 137\end{array}$

8 Considerações finais 139

$\begin{array}{ll}\text { Referências } & 143\end{array}$

$\begin{array}{ll}\text { Apêndice } & 148\end{array}$ 


\section{Lista de Figuras}

Figura 1: Amaciante Mon Bijou (Thiago Q. de Andrade, 2012)

Figura 2: Amaciante Concentrado Mon Bijou (Thiago Q. de Andrade, 2012) 55

Figura 3: Sabão em pó Mon Bijou (Thiago Q. de Andrade, 2012)

55

Figura 4: Sabão líquido Mon Bijou (Thiago Q. de Andrade, 2012) 56

Figura 5: Sabão líquido Ecobril (Thiago Q. de Andrade, 2012)

Figura 6: Refil do sabão líquido Ecobril (Aline R. Botelho, 2012)

58

Figura 7: Amaciante Ecobril (Thiago Q. de Andrade, 2012)

59

Figura 8: Sabão em pó Ecobril (Thiago Q. de Andrade, 2012)

59

Figura 9: Sabão líquido Biowash (Thiago Q. de Andrade, 2012)

61

Figura 10: Sabão em pó Biowash (Thiago Q. de Andrade, 2012)

61

Figura 11: Amaciante Biowash (Thiago Q. de Andrade, 2012)

62

Figura 12: Sabão em pó Ace (Thiago Q. de Andrade, 2012)

Figura 13: Sabão em pó Ace (Thiago Q. de Andrade, 2012)

Figura 14: Sabão líquido Ace (Thiago Q. de Andrade, 2012)

Figura 15: Sabão em pó Ariel (Thiago Q. de Andrade, 2012) 
Figura 17: Sabão em pó Ariel Ecomax (Thiago Q. de Andrade, 2012) 66

Figura 18: Amaciante Comfort (Thiago Q. de Andrade, 2012) 69

Figura 19: Amaciante concentrado Comfort (Thiago Q. de Andrade, 2012) 69

Figura 20: Refil do Amaciante concentrado Comfort (Thiago Q. de Andrade, 2012) 70

Figura 21: Amaciante Fofo (Thiago Q. de Andrade, 2012) 71

Figura 22: Amaciante concentrado Fofo (Thiago Q. de Andrade, 2012) 71

Figura 23: Refil do Amaciante concentrado Fofo (Thiago Q. de Andrade, 2012) 72

Figura 24: Sabão em pó Omo (Thiago Q. de Andrade, 2012) 73

Figura 25: Sabão líquido Omo (Thiago Q. de Andrade, 2012)

Figura 26: Sabão em pó Surf (Thiago Q. de Andrade, 2012) 75

Figura 27: Sabão líquido Surf (Thiago Q. de Andrade, 2012) 76

Figura 28: Sabão em pó Tixan Ypê (Thiago Q. de Andrade, 2012) 78

Figura 29: Sabão líquido Tixan Ypê (Thiago Q. de Andrade, 2012) 78

Figura 30: Amaciante Ypê (Thiago Q. de Andrade, 2012) 79

Figura 31: Amaciante concentrado Ypê (Thiago Q. de Andrade, 2012) 80

Figura 32: Sabão em pó Ypê Premium (Thiago Q. de Andrade, 2012) 81

Figura 33: Sabão líquido Ypê Premium (Thiago Q. de Andrade, 2012) 81 


\section{Tabela}

Tabela 1: Informações do PPL. (Unilever, 2011) 


\section{Apresentação}

O meio ambiente sempre foi para mim motivo de preocupação e cuidado. Ao ingressar na faculdade de Desenho Industrial, busquei demonstrar essa preocupação em projetos, fossem eles sem cola, menos tinta, materiais mais ecológicos, dentre outras alternativas.

Com este enfoque fiz meu projeto de graduação, cujo título era Design sustentável em embalagem - pesquisa, desenvolvimento e aplicação, com a proposta de criar embalagens a partir de materiais alternativos para uma marca de camisetas. Deste projeto como ponto de partida, comecei a analisar com mais dedicação o descarte e o que se fazia com o lixo produzido.

Ao ingressar no mestrado na Puc-Rio, resolvi focar meus estudos em cima do material que era descartado e que não era reaproveitado, principalmente em ambientes domésticos. Neste enfoque cheguei nos produtos de limpeza, que não são reutilizados porque acumulam cheiro e deixam resíduos, podendo ser inclusive, prejudicial a quem reutiliza suas embalagens.

A minha vinda para a cidade do Rio de Janeiro, e o fato de ter que fazer minhas próprias compras no supermercado, me fez perceber que propostas ecológicas estavam sendo comercializadas, ainda que de forma tímida.

A princípio, achei uma atitude excelente, que resolveria todos os problemas então entendidos por mim. Mas ao conversar informalmente com amigos e parentes, que também eram consumidores, soube que eles sequer notavam que esses produtos estavam à venda ou que eram diferentes dos demais.

Baseada nisto, surgiu a vontade de fazer esta dissertação, buscando penetrar no que os consumidores entendem por produtos ecológicos, e o quanto essas novidades têm influenciado suas atitudes de compra, se é que influenciam. 